\title{
On the Localization Phenomena of Snowfall
}

\author{
By Choji Magono \\ Department of Geophysics, Faculty of Science, Holkaido University, Sapporo \\ (Manuscript received 27 April, 1971)
}

\begin{abstract}
The localization phenomena of snowfalls in the winter monsoon season were studied from various points of view, namely cloud physics, laboratory experiment, radar meteorology and the satellite meteorology.

The results of the study are summarized as follows:

1. Snowfalls can occur over the Sea of Japan without any upglide effect by mountains.

2. The localization of snowfalls is produced by the convergence of snow clouds, because falling snow crystals are considered to be transported nearly horizontally by wind.

3. A meso-scale front is formed by two meso-scale air-masses, and a series of mesoscale cyclones is formed along the meso-scale front.

4. The formation mechanism of meso-scale cyclones may be explained by the classical model given by Bjerkness.

5. The orographic effect on the movement of snow clouds is considerably stronger than usually expected.

6. The snowfall is localized on an area where the wind speed is decreasing.

Actual examples of the localization of snow clouds and snowfalls were given as a result of the orographic effect.
\end{abstract}

\section{Introduction}

Recently the precipitation of localized heavy snowfalls has become a serious problem due to its impact on human activity, particularly on traffic conditions. However, forecasts of local snowfalls on a meso-scale are very difficult, particularly if the forecast sticks to the conventional method based on synoptic considerations alone. In order to make a more detailed forecast, a more thorough understanding of snowfall phenomena on a meso-scale is required, but it is difficult to obtain the necessary data by the conventional observation system. Particularly in the case of Japan, this is the more difficult because almost all snowfalls on the west side of Japan are brought in over the Sea of Japan.

Fortunately, it is now possible to obtain visual data of snowfalls and snow clouds over the sea by use of radar and satellite pictures. The author undertook to study the localization phenomena of snowfalls in the winter season, utilizing radar and satellite pictures. He thus noted that fundamental but very primitive physical considerations are required to under- stand the localization phenomena of snowfalls, in addition to meso-scale and cloud physical considerations. For instance, the area of an actual snowfall shows a considerable shift to the lee of the area of cloud formation, and the pattern of horizontal airflow in the unstable layer is entirely different from that in the laminar flow.

This paper describes the outline of the result of a study on the localization mechanism of snowfall, excluding the usual synoptic considerations.

\section{Localization of snowfalls over the sea}

2.1. Streak pattern of snow clouds in the winter monsoon period

It is now generally recognized that snow clouds in the winter monsoon period are distributed in streak or band patterns, as illustrated in Fig. 1 (Miura 1961, Higuchi 1963, Magono et al. 1966, and Tsuchiya and Fujita 1967). However, according to the results of analysis by Okabayashi (1966) and Magono and Kasai, snow clouds in the streak pattern are not directly related to the localization of 


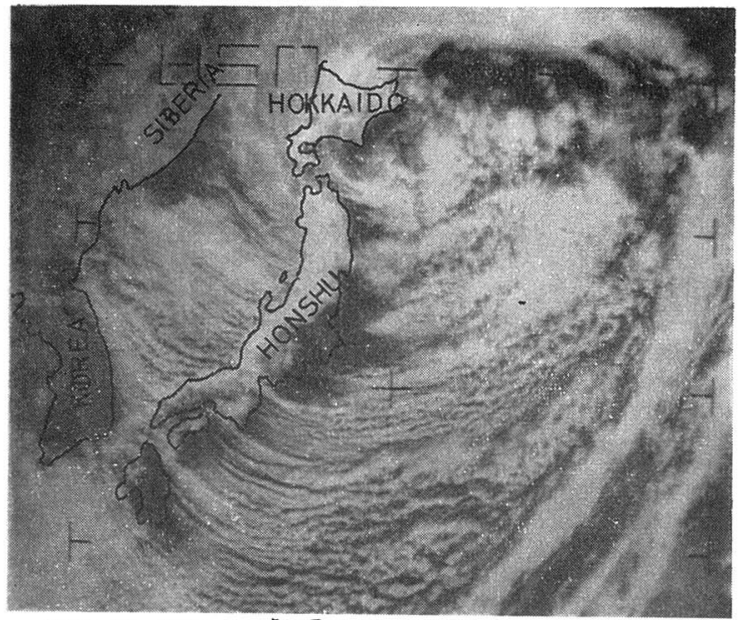

FEB. $10,1970 \quad 09^{\mathrm{n}} 25^{\mathrm{m}}$ ( J.S.T. ) $33.9^{\circ} \mathrm{N} 142.0^{\circ} \mathrm{E}$

Fig. 1. Cloud streak and meandering bands in the winter monsoon.

snowfalls, but bring snowfalls uniformly over the west side of Hokkaido and Honshu, Japan. It has been pointed out that heavy local snowfalls frequently occur toward the end of a monsoon period, when the so-called "west high, east low" surface pressure pattern begins to lose its identity and the streak pattern is disturbed.

Concerning this, it was supposed that some localization of snow clouds occurs over the sea toward the end of a monsoon period. This may be the cause of the difficulty of forecasting localized snowfalls in this period.

\subsection{Meandering of snow cloud bands}

It is generally considered that snow clouds in streak or band patterns have a structure of longitudinal convections (rolls) in parallel with the prevailing wind direction in a cloud layer; namely it may be that the cloud portions correspond to the ascending portions of convections and the cloudless portions to the descending portions of the convections, as may be supposed from classical model experiments. For example, Brunt (1951) demonstrated that the longitudinal rolls occurred in an unstable fluid layer under a strong vertical wind shear. This longitudinal roll pattern under the vertical shear was recently explained theoretically by Asai (1970).

It was confirmed by Magono et al. (1966) in natural clouds and by Tsuchiya and Fujita (1967) in satellite pictures that snow clouds in the monsoon period appear as streak patterns parallel to the vertical wind shear when the shear is strong. However, the streaks of snow clouds, or in other words the parallel longitudinal convections, usually take on a meandering pattern when they flow over a warmer sea surface, as seen in the satellite picture in Fig. 1. In this figure, it is observed that the streaks are straight immediately after leaving the Siberian Continent or the Japan Islands, but gradually change into a wavy and then a meandering pattern, as they proceed over the warmer surface of the Sea of Japan or the Pacific Ocean, and finally present ringshaped patterns.

This change in pattern was demonstrated by Magono and Yamazaki (1965) in a laboratory experiment where a thin cold layer of dry ice fog was made to flow over a warmer surface, as seen in Fig. 2. In the figure, the

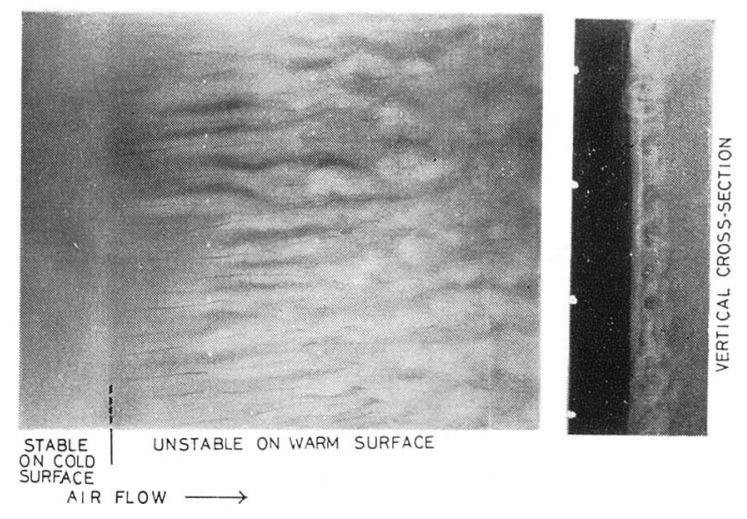

Fig. 2. Model experiment of cloud streak pattern under an unstable condition.

cold fog layer is flowing from over a cold surface at the left end to over a warm surface at right end. The cross section of the longitudinal convections are shown in the righthand picture.

In order to explain the meandering phenomenon of cloud bands, Mori and Uchida's laboratory experiment on longitudinal convections (1966) and Ogura and Yagihashi's numerical calculation (1969) are very useful. Based on the result of their studies, it may be considered that the flow speed is lowest in the updraft region of the convection and is highest in the region between the updraft and the downdraft. If the result is applicable to the natural clouds of streak patterns, as shown by short and long arrows in the left-hand half of Fig. 3, horizontal wind shears may occur between the clouded portion and the cloudless 


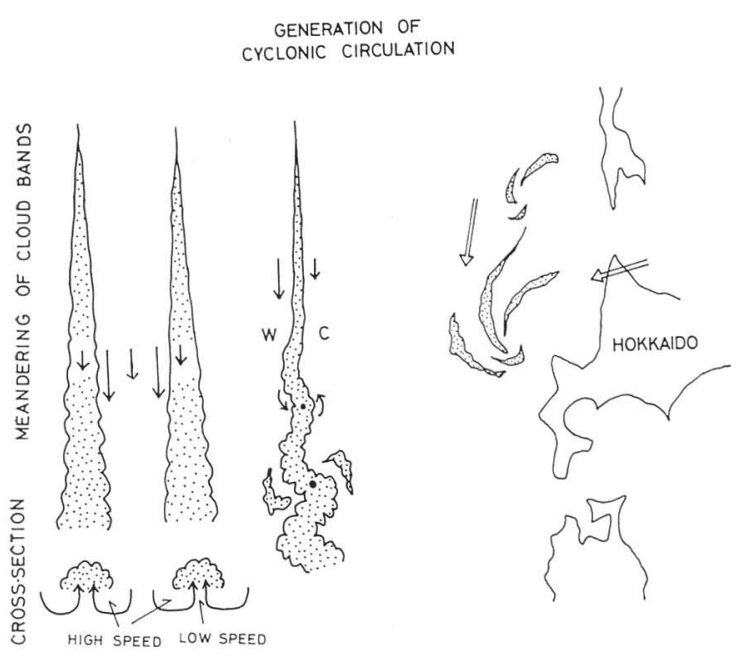

Fig. 3. Meandering of cloud bands owing to horizontal wind shear, and generation of cyclonic circulations.

portion, and as a result the cloud streak may take on a meandering pattern, owing to unstable shear wave effect. In the end it may tend to a very irregular Vénard Cell pattern, as the wind speed decreases.

\subsection{Meso-scale fronts over the sea}

Okabayshi (1969a) pointed out that mesoscale convergence bands over the Sea of Japan correspond to local heavy snowfalls on the west side of Japan, as shown by $A$ and $B$

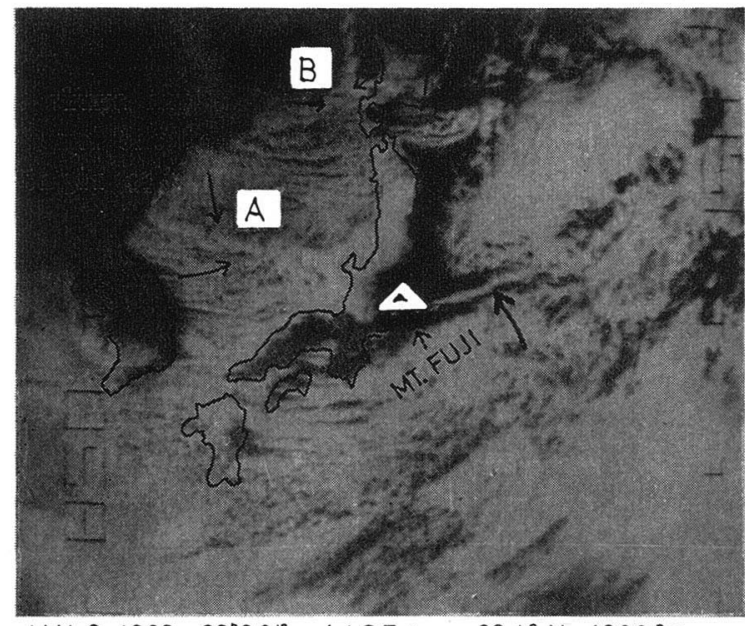

JAN. 2, $196909^{n} 08^{1 n} \quad$ (J.S.T. ) $33.4^{\circ} \mathrm{N} 138.8^{\circ} \mathrm{E}$

Fig. 4. Meso-scale fronts over the Sea of Japan, indicated by $A$ and $B$. A cloud band leeward of Mt. Fuji. in Fig. 4. However, in considering the disturbance, the author is of the opinion that it would be advisable to refer to them as mesoscale fronts or lines of discontinuity rather than as convergence bands, for the following three reasons.

1) From the streak patterns, it may be considered that line $A$ is a line of discontinuity or a border line between a meso-scale air-mass flowing out from the Siberian Continent and a small air-mass from the Korean Peninsula, and also that line $B$ is a line of discontinuity between another meso-scale air-mass from the continent and a very small air-mass flowing out from the Hokkaido Island.

2) It may be considered that line $A$ corresponds to the so-called "Hokuriku Line of Discontinuity" which frequently occurs over the sea near the west coast of Honshu Island, and that line $B$ corresponds to the so-called "Ishikari Line of Discontinuity" which occurs over the sea to the west of Hokkaido Island.

Kajikawa (1971) observed that when a snow cloud of the band type passed, remarkable changes occurred in the surface pressure, temperature and wind, and that the behavior of the change was similar to which accompanied the passage of a small squall line.

3) If we recognize the band of snow clouds as a line of discontinuity, it will be convenient in considering the disturbance of the line, as will be described later.

Such meso-scale lines of discontinuity as seen in Fig. 4 are frequently observed on other occasions, for example, in satellite pictures on Feb. 2, 1968, Jan. 7 and Feb. 23, 1969, Jan. 4 and 15, 1970.

\subsection{Generation of meso-scale cyclones} along a meso-scale front over the Sea of Japan

Since radar pictures became available, small cyclonic spiral patterns of snowy region have frequently been observed over the sea near the west side of Japan. See, for example, Miyazawa (1966), Kono and Magono (1967) and Saito et al. (1968). The radar pictures taken by the Fukui Domestic Meteorological Observatory in 1968 show a highly typical meso-scale disturbance with a cyclonic spiral pattern of snow-fall, as seen in Fig. 5. It may be noted that the pattern of disurbance is closely similar to that of synoptic cyclones along a front, although the cold air-mass is 

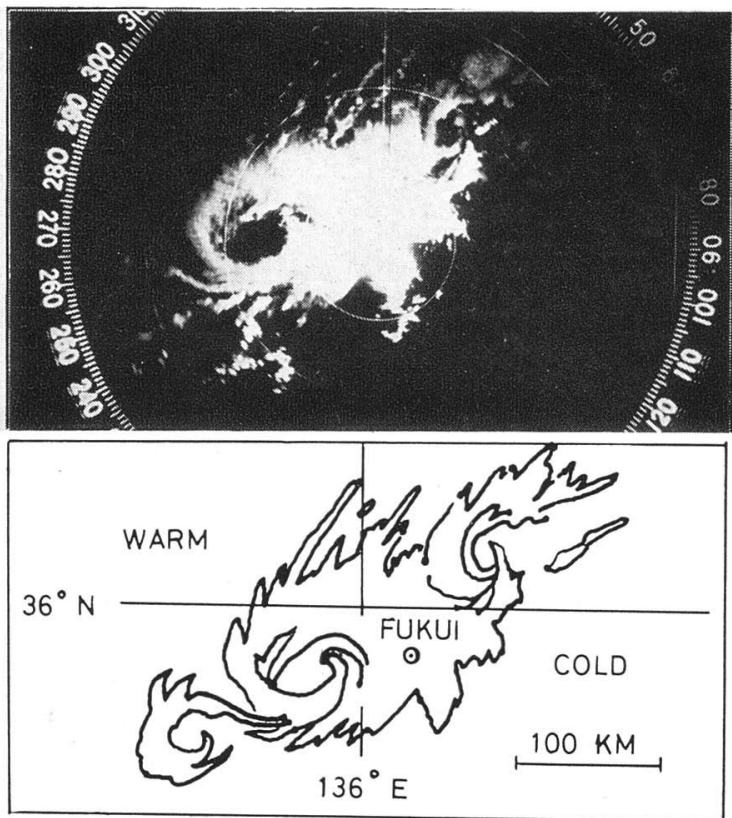

Fig. 5. Three meso-scale cyclones along a meso-scale front near Fukui, Feb. 9, 1968, $04^{\mathrm{h}} 52^{\mathrm{m}}$. After Fukui Met. Obs.

apparently on the south side of the front in the radar pictures.

Okabayashi (1969b) noted a series of mesoscale disturbances of cloud patterns occurring along a convergence band (meso-scale front) over the Sea of Japan in the satellite pictures, as shown by $A$ and $B$ in Fig. 4, and he pointed out that a meso-scale cyclone was detected at the south end of the band where a heavy snowfall occurred. Recently Okabayashi and Satomi (1970) reported that such small cyclones moved southward one trailing another, as schematically shown in the right-hand half of Fig. 3.

The observational data described above all suggest that the series of meso-scale cyclones is produced by a mechanism which is closely similar to the classical frontal model of cyclones given by Bjerkness. (Bjerkness J. 1957) In order to determine whether the classical model is applicable to such a meso-scale disturbance with a size of $100 \mathrm{~km}$ of so, it is necessary at least to confirm the existence of a temperature contrast and a cyclonic wind shift between the two meso-scale air-masses.

It is considered from the streak pattern of clouds in the satellite picture Fig. 4, that an air-mass is flowing out southward from the Siberian Continent and that another air-mass is flowing eastward from the Korean Peninsula, thus a meso-scale front $A$ is being formed over the central Sea of Japan by these small air-masses. It may also be considered from the figure that another meso-scale front $B$ is being formed between the continent and Hokkaido Island by the effect of two small airflows, namely by an eastward airflow from the continent and a westward airflow from Hokkaido.

Fig. 6 shows the surface weather map cor-

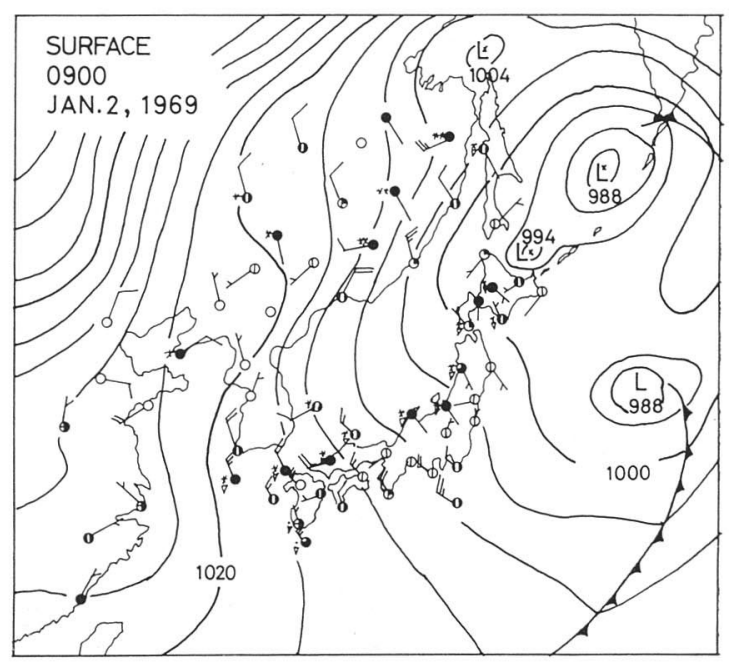

Fig. 6. Surface weather map, Jan. 2, 1969, $09^{\mathrm{h}} 00^{\mathrm{m}}$ JST.

responding to the satellite picture Fig. 4. It may be seen that as far as the mapping is concerned the surface winds show the airflow which is predicted in the satellite picture, and the wind systems on both sides of the mesoscale front show a convergence and a cyclonic wind shift, in case of both $A$ and $B$ fronts, although no synoptic fronts are mapped on the surface weather map.

It is difficult to compute the exact temperature difference between the two meso-scale airmasses in case of an $A$ front, because the airmasses are entirely over the sea. However, the horizontal distribution of isotherms at $850 \mathrm{mb}$ level on the same night shows that the air-mass which has flowed out from the peninsula is considerably colder than that from the continent, as seen in the isotherm distribution in Fig. 7. This temperature excess in the airflow from the continent is understandable, because the path of the southward airflow over the warm sea surface is considerably 


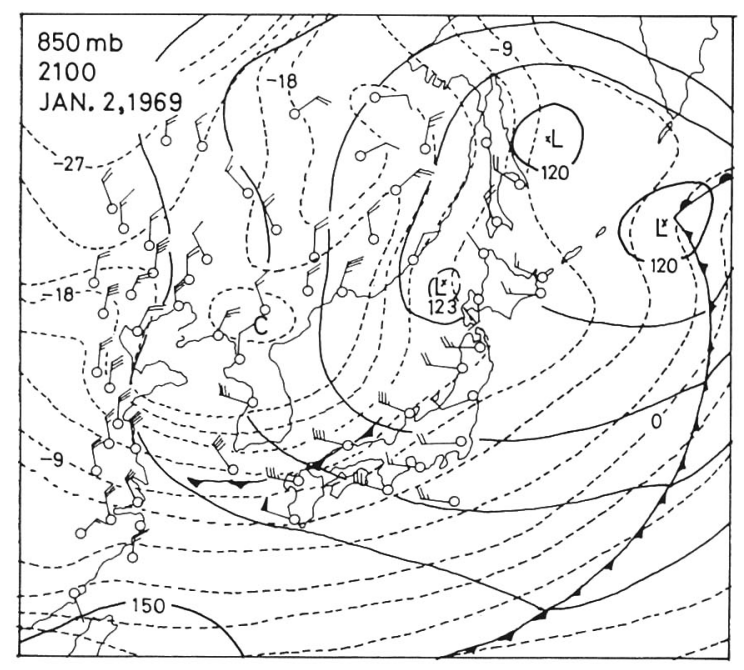

Fig. 7. $850 \mathrm{mb}$ weather map, Jan. 2, 1969, $21^{\mathrm{h}} 00^{\mathrm{m}}$ JST.

longer than that of the east-ward air-flow. Taking this into account, it may also be understood why the cold air-mass is located on the south side of the front in Fig. 5, although the date is different:

In case of a $B$ front, the horizontal distribution of isotherms in Figs. 6 and 7 shows that a small cold air-mass is located over Hokkaido Island and flowing out westward while another air-mass is flowing south-eastward, showing a convergence. But it is not clear which air-mass is colder.

In any event in both cases, it is qualitatively clear that there are both a temperature contrast and a cyclonic wind shift between the two meso-scale air-masses, although quantitative data are not available because the front is over the sea. Accordingly, all the available observational and analytical data suggest the possibility of an explanation of the formation mechanism of meso-scale cyclones by use of the classical theory given by Bjerkness, although his model is usually considered to be applicable to synoptic cyclones.

The meso-scale cyclones with a size of about $100 \mathrm{~km}$ which the author considers corresponds to the meso-scale disturbances with size of 100 to $250 \mathrm{~km}$ which were found by Matsumoto, Ninomiya and Akiyama (1967). But they are different from each other, because the former are related to the wavelength along a front, while the latter appear to be related to the distance between the lines of sonwfall bands.

\subsection{Other effects over the sea}

The two meso-scale fronts $A$ and $B$ described in $\$ 2.4$ invariably form in special regions, namely the front $A$ always starts from the northern part of the Korean Peninsula, and arrives at the west coast of Honshu Island, passing through the central Sea of Japan, while the front $B$ is always located over the sea to the west of Hokkaido Island. This tendency shows that the localization of clouds over the sea is also affected by the topography to the windward. Tsuchiya and Fujita (1967) pointed out that the topography of the Siberian Continent affects the distribution of the streak cloud patterns.

\section{Generation of snowfall over the sea}

It was believed for a long time that the sonwfall in the monsoon season in Japan was generated by the upglide motion along the mountainous areas of the west side of Japan. This is partly the case when the temperature of the air is not sufficiently cold to condense the vapor or to glaciate the cloud before it moves up the mountain slope. Snowfalls of this type are called Yamayuki (mountain snowfalls). However, it is now confirmed that clouds in the winter monsoon season are generally formed over the sea shortly after the cold air leaves the Siberian Continent, and that the snow crystals are formed over the sea before the clouds arrive over Japan. This is particularly the case in snowfalls on the west coast of Hokkaido.

According to the results of Nakaya's laboratory experiment on artificial snow crystals (1954a), the snow crystals of the dendritic type have the highest growth rate among the various types, for snow crystals develop into dendritic form at a temperature range of -13 to $-17^{\circ} \mathrm{C}$, and moreover the snow crystals grow most rapidly in this temperature range. This was later explained theoretically by Houghton (1950).

On the other hand, one ice nucleus is required to form one snow crystal, and the concentration of ice nuclei depends on the air temperature; in other words, the colder the temperature, the higher the ice nucleus concentration. According to numerous observational data obtained hitherto, it is considered that the concentration is sufficient to glaciate supercooled clouds in temperatures lower than 
$-20^{\circ} \mathrm{C}$. It is, therefore, considered on the basis of cloud physics that snow crystals are formed in a cloud when its top reaches an air layer colder than $-20^{\circ} \mathrm{C}$. In this case, the cloud usually contains the dendritic temperature region of -13 to $-17^{\circ} \mathrm{C}$.

It is a matter of course that the surface air temperature must be lower than $0^{\circ} \mathrm{C}$, in order to produce a snowfall on the ground surface. The lapse rate of air temperature in the lower air layers is usually about $7^{\circ} \mathrm{C} / 1 \mathrm{~km}$ during snowfalls near the sea. Accordingly we have arrived at the conclusion that clouds with tops higher than $3 \mathrm{~km}$ are required for snowfalls, when the surface air temperature is about $0^{\circ} \mathrm{C}$. In an attemp to verify this, utilizing the air temperature at $850 \mathrm{mb}$ level where the horizontal distribution of temperature is usually give, a temperature of $-11^{\circ} \mathrm{C}$ seems to be critical. According to the results of analysis, the $850 \mathrm{mb}$ temperature was always lower than $-12^{\circ} \mathrm{C}$ when heavy snowfalls occurred on the west side of Honshu. In the case of Hokkaido, the temperature is always colder than $-12^{\circ} \mathrm{C}$, because the surface air temperature is always colder than $-12^{\circ} \mathrm{C}$, because the surface air temperature is colder than $0^{\circ} \mathrm{C}$.

If the necessary conditions for the formation of snow crystals in the clouds over the sea are satisfied, whether a snowfall reaches the west side of Japan or not is determined solely by the wind direction, because the fall speed of snow crystals is very low, as will be described later. According to the results of statistical analysis by Ishihara (1967), the most important factors in the occurrence of a snowfall are the air temperature and wind direction. His results strongly support the author's consideration based on cloud physics.

The terminal fall speed of snow crystals are as low as 0.3 to $1 \mathrm{~m} / \mathrm{sec}$ (Nakaya 1954b, Magono 1954), while the wind speed in cloud layers is as high as 10 to $20 \mathrm{~m} / \mathrm{sec}$; in other words, the wind speed is 20 to 30 times higher than the fall of snow crystals. Therefore it may be considered that snow crystals over the sea are transported horizontally, neglecting their falling. In view of this, it is easily understood why snowfall occurs $50-60 \mathrm{~km}$ to the lee of its corresponding cloud formation area.

Because the air temperature of a cold airmass flowing out of the Siberian Continent in the winter season is already low enough to produce snow, snowfall occurs over the Sea of Japan without any updraft such as upglide motion along the mountain slopes; it is determined by the wind direction alone whether the snowfall occurs uniformly over the west side of Japan or concentrates in a particular region. Snowfalls of this type are called Satoyuki (lowland snowfalls). However, the actual localization of snowfall on the land is also affected by orographic conditions such as the distribution of mountains.

\section{General effect of the land on the locali- zation of snowfalls}

Among the orographic effects on snowfalls, only the upglide effect and the barrier effect of mountains have been considered to date, but further fundamental considerations are required for a complete understanding of the localization phenomena of snowfall on the land.

\subsection{Flowing patterns under unstable con- ditions}

To date, both model experiments and theoretical studies on the barrier effect have been made in a laminar flow, namely in thermally stable conditions, but the airflow over the sea in the winter occurs under thermally unstable conditions. It was, therefore, difficult at first to understand the cloud patterns in satellite pictures.

As stated in $\S 2$, the flowing of a cold airmass invariably takes place under thermally unstable conditions which consist of many parallel longitudinal convections. Therefore, the pattern of clouds is considered to be entirely different from the results of studies in a laminar flow. Yamazaki and Magono (1968) made a laboratory experiment with regard to an airflow around an obstacle under unstable conditions which was the same as in \$2.1. The result of the experiments may be summarized into the following two figures.

The upper picture in Fig. 8 shows a flowing pattern of dry ice fog around an obstacle with a size of $2 \mathrm{~cm}$ under stable conditions, and the lower picture shows the vertical section of the pattern shown in the upper picture. The lines over the flow are layers of tobacco smoke introduced to show the air motion over the flow. In the figure, one may see that the heavy dry ice fog went over the obstacle very easily, and a hook-shaped pattern of updraft 
TOP VIEW

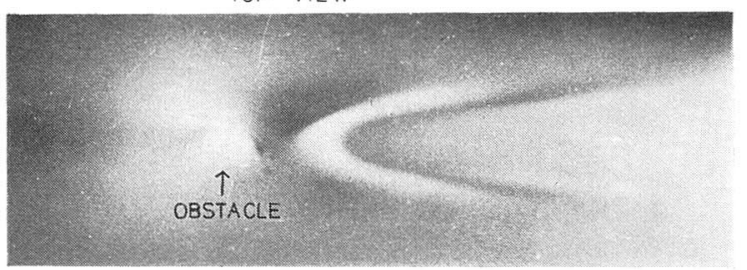

AIRFLOW $\longrightarrow$ SIDE VIEW

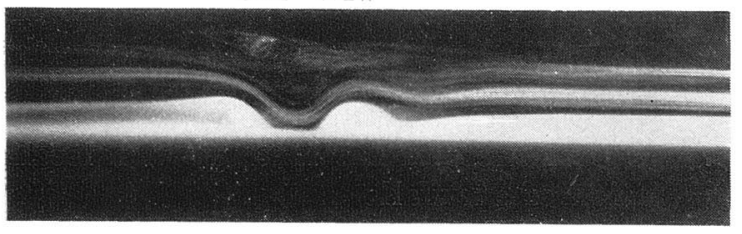

Fig. 8. Airflow pattern around an obstacle in a laminar flow.

TOP VIEW

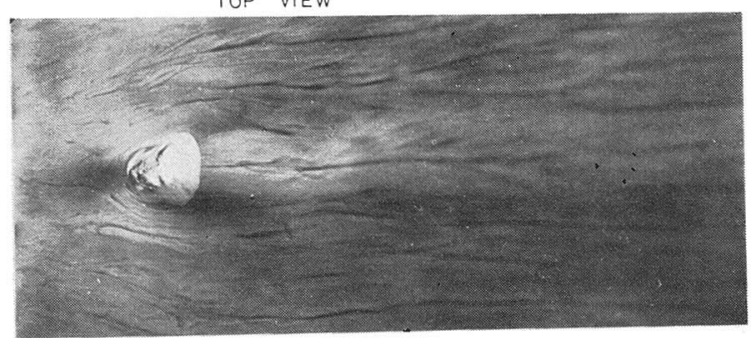

AIRFLOW $\longrightarrow$

OBLIQUE VIEW

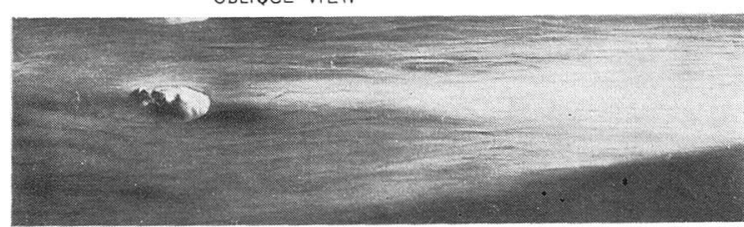

Fig. 9. Airflow pattern around an obstacle under a thermally unstable condition.

region was formed to the lee of the obstacle.

On the other hand in the case of thermally unstable conditions, the flowing pattern was entirely different, as seen in Fig. 9. The thermally unstable condition was produced by heating the surface of a black floor by radiation from strong electric tubes. The upper picture of Fig. 9 shows the flowing pattern of the same dry ice fog around the same obstacle in unstable conditions. As may be seen, the fog was unable to get over the obstacle, but passed around the side of the obstacle. A thick cloud band (longitudinal convection band) was formed to the lee of the obstacle.
This cloud band can be more clearly seen in the oblique view in the lower picture in Fig. 9.

Considering the flowing patterns given abcve, it may be understood that the cloud pattern in the cold air-mass is entirely different from the expected; particularly it is noted that the barrier effect is considerably stronger in case of unstable conditions. The author considers that this strong effect may be caused by convection, namely that negative momentum is transported to the cloud layer from the land surface by vertical air motion, as will be discussed below.

\subsection{Vertical transfer of negative momen- tum from the land surface}

The wind speed near the land surface is much lower than that in the cloud layer, owing to the friction against the land surface, including mountains. If the vertical exchange of momentum is made strongly under thermally unstable conditions as in the cumulus cloud condition, the negative momentum (lower wind speed) is transported upward, thus the wind speed in the cloud region becomes lower than that in the surrounding cloudless region. Accordingly, the horizontal speed of movement of the clouds therselves is lower than the wind speed at the cloud level.

This consideration is useful in understanding why the path of snow clouds is strongly affected by the distribution of mountains. It is generally observed that when a band of snow clouds passes over a valley, they avoid mountains when they arrive at the land, even if the clouds are considerably higher than the mountains. As a result, snowfalls become heavier in low land areas than on the mountains. This is another explanation of the generation mechanism of the low land snowfall. The effect of mountains on the snowfall area as a barrier will be described later again as the 'barrier effect'.

\subsection{Cooling effect of the surface of land}

The surface temperature of the sea is warmer than $4^{\circ} \mathrm{C}$; therefore the cloud layer over the sea is heated from below, and then cooled from the bottom after it has hit the land, because the surface temperature of the land covered by snow is usually several degrees colder than $0^{\circ} \mathrm{C}$. This temperature contrast is very great, compared with the usual expectations. It is therefore considered that a 


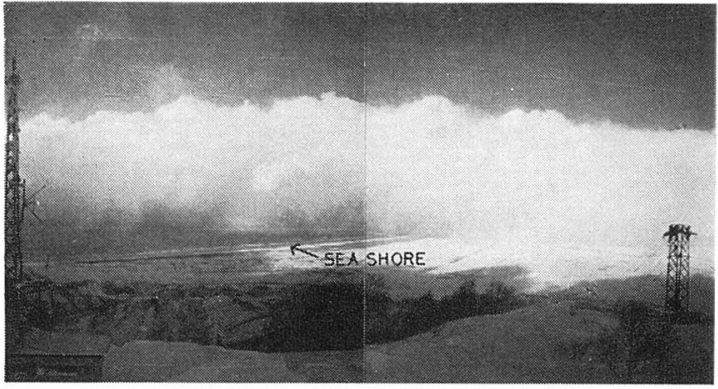

Fig. 10. Side view of clouds of a band type from Mt. Teine (1023 $\mathrm{m}$ altitude).

cloud becomes rapidly inactive when it comes over the land, even if it was active over the sea. This change in the activity of clouds can be clearly seen if we observe the changes in the side view of a cloud when it comes over a seashore.

Fig. 10 shows the side view of snow clouds floating across a seashore. The wind was blowing from left to right, that is, from the Ishikari Bay adjoining the Sea of Japan to the Ishikari Plains, but the shape of the clouds was steady in time with respect to the seashore. In the figure, it may be seen that the snow clouds were active and took a stratocumulus form over the sea, but became diffused as they passed inland, indicating that they became inactive. This rapid change in cloud form is partially caused by the heavy snowfall that occurred immediately after the clouds hit the seashore. Perhaps the fall of snow crystals over the sea was prevented by the upward air motion in the clouds.

Another important effect of the land is the production of flowing out of cold and dry air from over the land, because the air is cooled over the land, and the snow and moisture are removed from the air by the snowfall. A remarkable flowing out on a large scale was already described in $\S 2.3$, but such a phenomenon is frequently observed on a smaller scale in satellite pictures in the winter season. For example, in Fig. 1 may be seen several cloudless areas to the lee of Honshu and on the south side of Hokkaido Island. From the streak pattern in the cloudless areas, it may be concluded that a cold but dry air-mass is flowing out from the land.

If the direction of the flowing out converges, a meso-scale convergence band of clouds is formed, as over the Mamiya Straits between the Siberian Continent and Hokkaido Island,

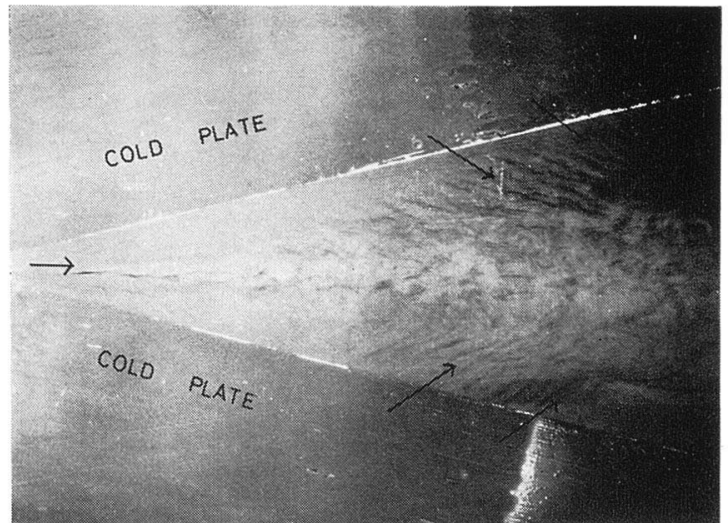

Fig. 11. Model experiment of a convergence of cloud bands as produced by outflow of two cold air-masses.

and over the sea to the south of Hokkaido Island, for which see Fig. 4. This convergence band is easily demonstrated by a laboratory experiment. Fig. 11 shows a pattern of convergence bands thus formed. In the figure, cold air is flowing to the right over a warmer surface of a fan-shaped metalic plate between two colder plates. The air is cooled over the colder plates. As a secondary effect, a smallscale cold air current is flowing out from the two colder plates, as seen at the right end of the figure. Consequently a convergence band is formed, as seen at the center of the figure. When the two plates are not colder, no convergence band is formed.

\subsection{Concentration of snowfall by decrease in wind speed (stagnant effect)}

It is frequently observed that sand particles precipitate and concentrate on the bottom of a river where the flow speed is lower, or the water is stagnant. Such a concentration phenomenon is also observed around an obstacle in the case of blowing snow, namely the snow particles are concentrated and piled up in places close to the obstacle where horizontal air motion is decreased. This is the phenomenon of snowdrifts. Here a question arises as to where such concentrations of snowfall also occur on a meso-scale.

As described in $\S 3$, snow crystals can be considered to be transported horizontally by wind when they are falling from a cloud. If we assume that the wind speed is $10 \mathrm{~m} / \mathrm{sec}$ uniformly from the ground surface to the cloud layer except for the turbulent layer with a depth of $100 \mathrm{~m}$ immediately above ground sur- 


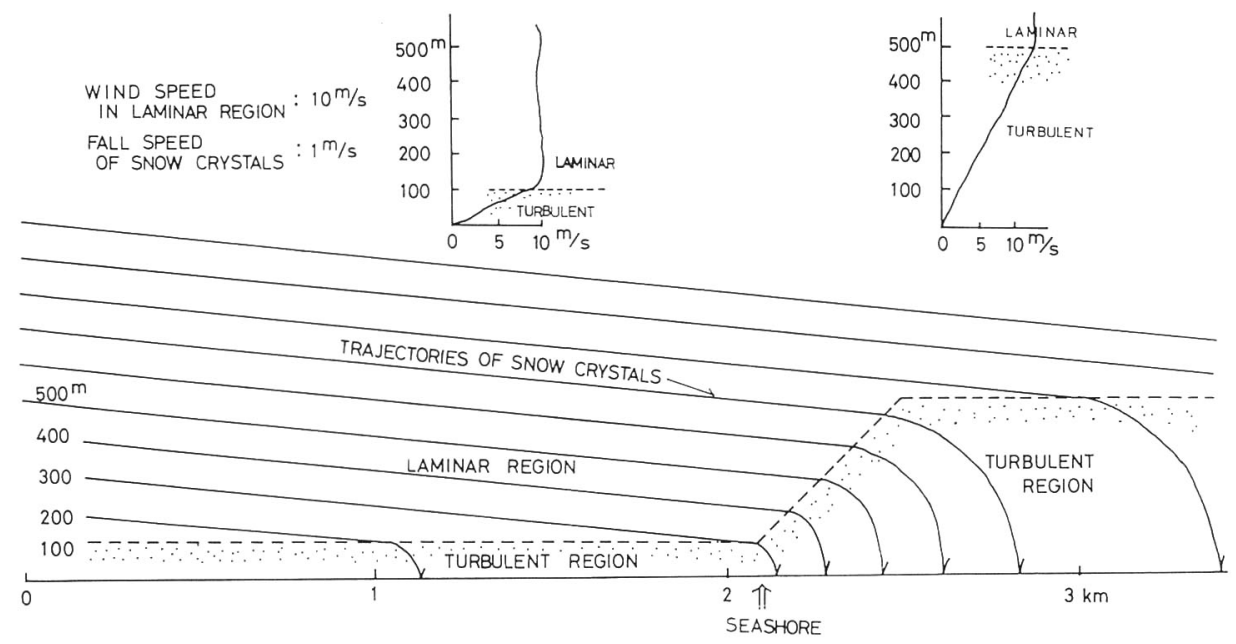

Fig. 12. Concentration of snowfall due to decrease in wind velocity.

face, as shown in the left top of Fig. 12, and if we assume that snow crystals with a fall speed of $1 \mathrm{~m} / \mathrm{sec}$ are steadily transported from the left, then the trajectory of the snow crystals would be as shown in the left-hand part of the figure where the vertical and horizontal axes mean the height above the surface and the horizontal distance, respectively.

If an air-mass containing snow clouds arrives at the land (at $2 \mathrm{~km}$ in the horizontal axis) and the turbulent layer extends upward to the $500 \mathrm{~m}$ level, owing to the increasing roughness of the land, as shown at the right top of the figure, then the trajectory of the snow crystals will change and take courses as shown in the right-hand part of Fig. 12. Thus it is easy to understand why the snowfall is concentrated by five times in the region between 2 and $3 \mathrm{~km}$ in the horizontal axis where the wind speed in the lower layer markedly decreases.

In a turbulent layer, both updraft and downdraft portions are present in a disorderly manner. The falling of snow crystals is impeded by the updraft, but this is offset by the downdraft in other regions, depending on the scale of the air disturbance.

\section{Localization of snowfall bp orographic effect}

\subsection{Barrier effect of mountains}

It may be convenient to describe the vertical structure of the typical snow cloud prior to discussing the barrier effect of mountains

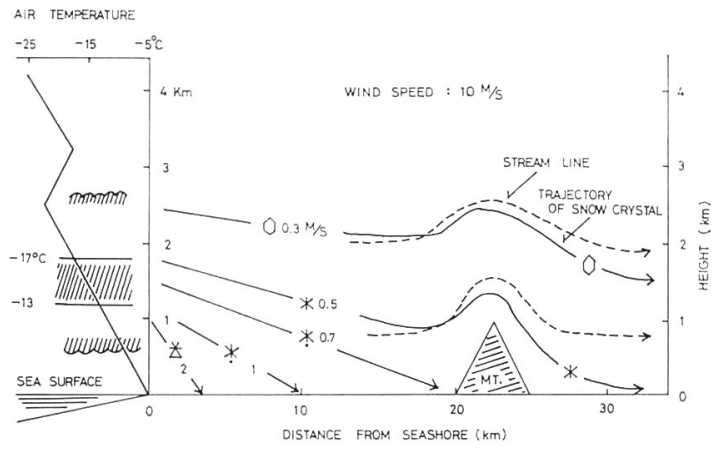

Fig. 13. Formation of snow crystals in a cloud over sea, and their trajectories, as predicted.

near the seashore. At the left end of Fig. 13, a typical temperature profile of a snow cloud over the sea is given. The vertical and horizontal axes show the height above the sea ?evel in $\mathrm{km}$ and air temperature in ${ }^{\circ} \mathrm{C}$, respectively. The top and bottom of the cloud layer are shown schematically and the temperature range for the dendritic type of snow crystals is shown by the hatched region. Generally the top of the snow clouds on the west side of Hokkaido is suppressed by a strong temperature inversion.

We assume that actual snowfalls occur immediately after the cloud arrives over the seashore, and that the wind speed is $10 \mathrm{~m} / \mathrm{sec}$ homogeneously throughout the air layers. Then the heaviest snow particles (graupel) will begin to fall with a fall speed of about $2 \mathrm{~m} / \mathrm{sec}$ from the bottom of the cloud and will arrive at the ground surface about $3 \mathrm{~km}$ 
from the seashore. Then densely rimed snow crystals with a fall speed of $1 \mathrm{~m} / \mathrm{sec}$ will arrive at the ground about $10 \mathrm{~km}$ from the seashore. Lightly rimed snow crystals will arrive at the foot of the mountain, as shown in the center of Fig. 13.

Ascending air currents in front of the mountain and descending currents behind the mountain are considered due to the mountain, as shown by broken lines in the right portion of the figure. Ice crystals with a fall speed of $0.3 \mathrm{~m} / \mathrm{sec}$ and non-rimed light snow crystals are transported upward again in front of the mountain and fall far to the lee of the mountain with trajectories as shown by the arrows. If this idea were correct, snow crystals would not fall in front of the mountain but accumulate on the other side. But this is not the case. This error comes from the assumption that wind speed is homogeneous both vertically and horizontally.

In actual cases, the wind speed in the layer lower than the mountain must be considerably weakened by friction, as illustrated by a broken line at the left top corner in Fig. 14.

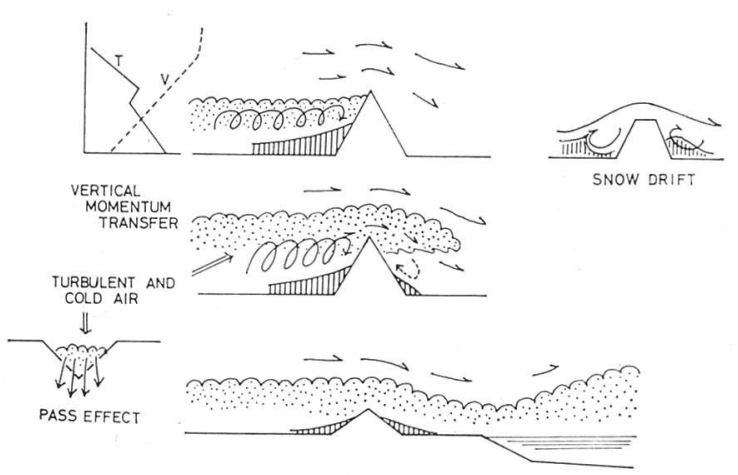

Fig. 14. Barrier effect of mountains, pass effect and snowdrift pattern.

If the top of a snow cloud is lower than the mountain, the cloud would not be able to get over it, as shown schematically in the upper part of the figure, because the air carrying the snow cloud is colder and heavier. In this case, the snowfall would occur only in front of the mountain.

A question may be raised with regard to the foregoing discussion, concerning additional traces of colder air lower than the mountain, because if the cold air can not pass over the mountain, an increasing accumulation of air

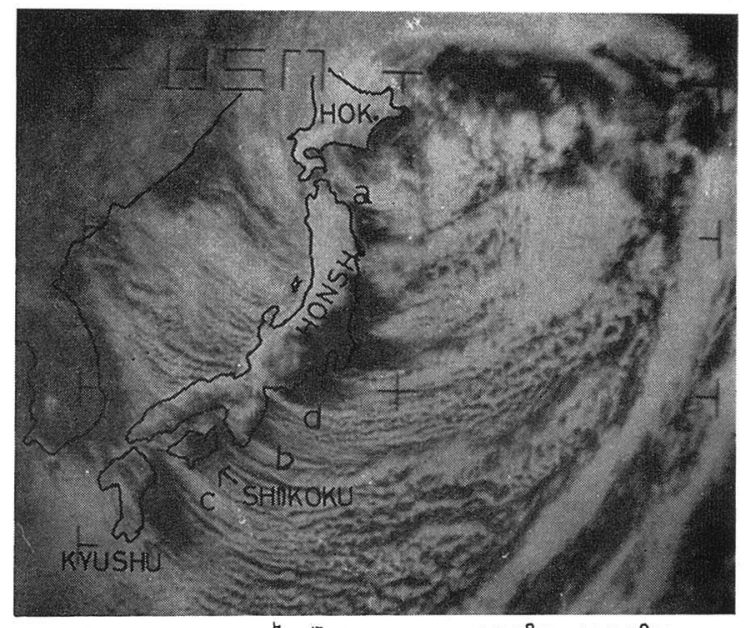

FEB. $10,1970 \quad 09^{\mathrm{h}} 25^{\mathrm{in}}$ ( J.S.T. ) $33.9^{\circ} \mathrm{N} \quad 142.0^{\circ} \mathrm{E}$

Fig. 15. Canal effect indicated by $a, b$ and $c$, and pass effect indicated by $d$.

in front of the mountain should occur. However, if the wind speed is higher in the upper layers, as shown in Fig. 14, it may be considered that the wind in the lower layer are compressed from above, and the kinetic energy of the wind in the lower layers would be dissipated as frictional heat energy. This phenomenon was also recognized by Förchtgott (1949), a glider pilot.

\subsection{Canal or pass effect}

It is frequently observed in satellite pictures that cold and heavy air flows out through a canal or over a valley or a pass, taking on a cloud band pattern, because of the difficulty of passing over the mountain. For examples of canal effect, see Fig. 15, where the Tsugaru Canal between Hokkaido and Honshu is shown by $a$, the Naruto Canala betweeon Honshu and Shikoku by $b$ and the Bungo Canal between Shikoku and Kyushu by $c$, and for the pass effect, the neck between Tsuruga and Nagoya is shown by $d$, etc.

The effect of topography on the cloud pattern over the Sea of Japan was pointed out by Tsuchiya and Fujita (1967), as already described. This may also be the pass effect.

\subsection{Peak effect}

Frequently a single cloud band is formed to the lee of Mt. Fuji as indicated in Fig. 4, and sometimes observed to the lee of the mountains in the south-western part of Hokkaido. Because the cloud band corresponds to the up- 
draft region of convection, the formation mechanism of the cloud band to the lee of mountain peak may be easily understood from the result of Yamazaki and Magono's experiment (1966) in Fig. 9, where a longitudinal convection band was formed to the lee of an obstacle.

The cloud band to the lee of Mt. Fuji was also discussed as a convergence line by Nakayama et al. (1969). They considered that the line was formed by the bending effect of a vortex tube.

\subsection{Convergence effect}

As described in $\$ 4.3$, if two different systems of cold air flow from different directions to converge upon one another, a small convergence band of clouds is formed, as demonstrated in Fig. 11. The meso-scale fronts $A$ and $B$ described in $\$ 2.4$ are due to this convergence effect on a greater scale.

\subsection{Edge effect}

Matsumoto (1967) found a hook-shaped cloud pattern around Sado Island in an aerial picture, and he explained this as a result of the bending of a vortex tube. Kasai (1966) considered that the cloud band over Ishikari Bay was formed by the effect of mountains on the south side of the bay. The author considers that such a cloud band around a mountain or an island may be formed by a 'shoulder effect', although the formation mechanism has not yet been clarified. It may be advisable at the moment to call it the 'edge effect' as proposed by Matsumoto.

\subsection{Stagnant effect}

Endow and Akiyama (1970) made mesoscale network observations of snowfalls at Otaru City near Sapporo, Hokkaido. According to their results, the snowfall has a tendency to localize on an area where stream lines of wind are disturbed, namely in a convergence area, a divergence area and a randomly disturbed area of the stream lines. Because the wind speed (horizontal component) is decreased in such regions, it may be said that the snowfall concentrates in an area where the air is stagnant. The tendency may be explained by the consideration given in \$4.4.

Okabayashi (1966) pointed out that if a valley is open for snow clouds coming in from the sea, they come in along the valley, and then snowfall occurs concentrating at the inner end of the valley. This may be because the wind speed decreases at the end of the valley. If this be the case, this localization of snowfall at the end of the valley is also caused by the stagnant effect.

\subsection{Snowdrift}

As is well known, the snowdrift is a phenomenon by which the snow piles up in a hook-shaped pattern around a house or building. The snowdrift is explained by considering the horizontal distribution of wind around the house; namely the snow is moved away from areas of high wind speed and is piled up where the wind speed is low. This pattern of snowdrift is formed by a very small-scale stagnant effect.

\section{Concluding remarks}

If it is established, on the basis of cloud physics, that snow crystals are formed over the sea without any upglide effect, it will then be accepted that the snow crystals are transported nearly horizontally and converge on a zone when two wind systems blow on converging courses. In this case, convergence is not related to cloud formation directly.

The airflow in unstable conditions receives two kinds of frictional effect of the land (including mountains). One is the deviation in the flowing direction which causes convergence of snowfalls in some cases. Another is the decreasing effect in the wind speed. The latter also makes concentrated snowfalls.

In this paper, the usual synoptic consideration was not made, but it is a matter of course that localization of snowfall on a mesoscale is based on synoptic phenomena, when it is viewed in a large scale. The study here attempted is qualitative and phenomenological, but the author thinks that such primitive considerations are necessary to start a new study and will be useful in understanding the meso-scale localization phenomena of snowfall.

\section{Acknowledgements}

Several years ago, the late Prof. Shyono and the present author talked about the forecast of local snowfall and arrived at the conclusion that a quite different line of approach from what the accepted synoptic meteorology offers would be required to understand local heavy concentrated snowfalls. It is the author's 
great pleasure to dedicate this paper to him.

Many data which have not yet been printed were used in this paper. The author wishes to express his thanks for those who kindly offered the use of their valuable data.

This study was made part of the section "The Abnormal Meteorology" in the Special Study Program on Natural Disasters of sponsored by the Educational Ministry of Japan, and also as part of "The Study on Sea and Lake Effect Snowfalls" under the U.S.-Japan Science Cooperative Program.

\section{References}

Asai, T., 1970: Three-dimensional features of thermal convection in a plane Couett flow. Jour. Met. Soc. Japan, Ser. II 48, 18-29.

Brunt, D., 1951: Experimental cloud formation, Compedium of Meteorology, 1255-1262.

Bjerkness, J. et al., 1957: Dynamic Meteorology and Weather Forecasting. Amer. Met. Soc., $313-359$.

Endow, T. and T. Akiyama, 1970: The effect of topographical wind affecting meso-scale snowfall areas. Tenki, 17, 429-433.

Föchtgott, J., 1949: Wave streaming in the lee of mountain ridges. Bull. Met techécosl, Prague, 3, 49.

Higuchi, K., 1963: The band structure of snowfalls. Jour. Met. Soc. Japan, Ser. II, 41, 5370.

Houghton, H. G., 1950: A preliminary quantitative analysis of precipitation mechanism. Jour. Met., 'y, 363-369.

Ishihara, K., 1967: Study of Statistical Analysis and Forecast of Snowfall on the Area of the Japan Sea Side of Central Japan. Japan Met. Agen.

Kajikawa, M., 1971: On the time variation of precipitation particles from shower snow clouds. Geophys. Bull. Hokkaido Univ., No. $25,155-165$.

Kasai, T., 1966: On the orographic effect on the cloud street in the winter monsoon season. Proc. 1966 Autumnal Annual Meet., Met. Soc. Japan, No. 109, 16-17.

Kono, Y. and C. Magono, 1967: A study on the small-scale cyclone on the Ishikari Bay. Geophys. Bull. Hokkaido Univ., 18, 71-81.

Magono, C., 1954: On the falling velocity of solid precipitation elements. Sci. Rep. Yokohama Nat. Univ., Sec. I, 33-40.

Magono, C., K. Kikuchi, T., Kimura, S. Tazawa and T. Kasai, 1966: A study on the snowfall in the winter monsoon season in the Hokkaido with special reference to low land snowfall. Jour. Fac. Sci., Hokkaido Univ., Ser. VII, 2, 287-308.
Magono, C. and T. Yamazaki, 1965: A laboratory model experiment of the cloud bands over the Sea of Japan, II. Proc. 1965 Autumnal Annual Meet., Met. Soc. Japan, No. 145, 82-83.

Matsumoto, S., 1967: Orographic edge effect on the down-stream cumulus activity. Jour. Met. Soc. Japan, Ser. II, 45, 500-503.

Matsumoto, S., K. Ninomiya and T. Akiyama, 1967: Cumulus activities in relation to the mesoscale convergence field. Jour. Met. Sco. Japan, Ser. II, 45, 292-305.

Miura, S., 1961: Symposium on the mechanism of snowfall. Tenki, 8, 325-327.

Miyazawa, S., 1967: On vertical mesoscale disturbances observed during the period of heavy snow or rain in the Hokuriku District. Jour. Met. Soc. Japan, Ser. II, 45, 166-176.

Mori, Y. and Y. Uchida, 1966: Forced convective heat transfer between horizontal plates. Int. Jour. Heat Mass Transfer, 9, 83-98.

Nakaya, U., 1954a: Snow Crystals, natural and artificial. Harvard Univ. Press, 248.

Nakaya, U., 1954b: Ibid 111.

Nakayama, A., H. Ishizaki, K. Inoue and H. Hamada, 1969: On the convergence line caused by orographic effect. Tenki, 16, 109-114.

Ogura, Y. and A. Yagihashi, 1969: A numerical study of convection rolls in a flow between horizontal parallel plates. Jour. Met. Soc. Japan, Ser. II, 47, 205-217.

Okabayashi, T., 1966: Symposium on the snowfall in areas along the Sea of Japan. Tenki, 13, 440-443.

12, 1969a: Photographs of heavy snowfall on the Japan Sea side on Jan. 2, 1969. Tenki, 16, 79-80.

$-1969 \mathrm{~b}$ : On the convergent band cloud appeared on the satellite pictures and the small-scale low. Tenki, 16, 33-34.

Okabayashi, T. and M. Satomi, 1970: The relation of convergent band clouds to small-scale cyclones in heavy snowfall. Proc. 1970 Spring Annual Meet., Met. Soc. Japan No. 304, 117.

Saito, M., F. Ginnoka, H. Matsuda, M. Satomi and T. Obana, 1968: Radar analysis of the snowfall in the vicinity of Ishikari Bay in Hokkaido. Tenki, 15, 42-50.

Tsuchiya, K. and T. Fujita, 1967: A satellite meteorological study of the evaporation and cloud formation over the Western Pacific under the influence of the winter monsoon. Jour. Met. Soc. Japan, Ser. II, 45, 232-250.

Yamazaki, T. and C. Magono, 1968: A laboratory model experiment of the cloud band, III. Proc. 1968 Autumnal Annual Meet., Met. Soc. Japan, No. 227, 136. 